\title{
A predictive score for 30-day survival for patients undergoing major lower limb amputation for peripheral arterial obstructive disease
}

\author{
Marco Franchin ${ }^{1} \cdot$ Vincenzo Palermo $^{1} \cdot$ Carlo lannuzzi $^{1} \cdot$ Nicola Rivolta $^{1}$. Gaddiel Mozzetta ${ }^{1} \cdot$ Matteo Tozzi $^{1}$. \\ Ruth L. Bush ${ }^{2}$. Gabriele Piffaretti ${ }^{1}$
}

Received: 2 April 2021 / Accepted: 7 May 2021 / Published online: 13 June 2021

(c) The Author(s) 2021

\begin{abstract}
To analyze outcomes following major lower extremity amputations (mLEAs) for peripheral arterial obstructive disease, gangrene, infected non-healing wound and to create a risk prediction scoring system for 30-day mortality. In this single-center, retrospective, observational cohort study. All patients treated with above-the-knee amputation (AKA) or below-the-knee amputation (BKA) between January 1st, 2010 and June 30th, 2018 were identified. The primary outcome of interest was early ( $\leq 30$ days) mortality. Secondary outcomes were postoperative complications and freedom from amputation stump revision/ failure. We identified 310 (77.7\%) mLEAs performed on 286 patients. There were $188(65.7 \%)$ men and $98(34.3 \%)$ women with a median age of 79 years (IQR, 69-83 years). We performed 257 (82.9\%) AKA and 53 (17.1\%) BKA. There were 49 $(15.8 \%)$ early deaths, which did not differ among the age quartiles of this cohort (15.4\% vs. $14.3 \%$ vs. $15.4 \%$ vs. $19.5 \%$, $P=0.826)$. Binary logistic regression analysis identified age $>80$ years (OR 2.24, 95\% CI 1.17-4.31; $P=0.015)$, chronic obstructive pulmonary disease (OR 2.12, 95\% CI 1.11-4.06; $P=0.023$ ), and hemodialysis (OR 2.52, 95\% CI 1.15-5.52; $P=0.021$ ) to be associated with early mortality. The final score (range $0-10$ ) identified two subgroups with different mortality at 30 days: lower-risk (score $<4,10.8 \%$ ), and higher-risk (score $\geq 4: 28.7 \%$; OR 3.2, 95\% CI 1.63-6.32; $P<0.001$ ). In our experience, mLEAs still have a $14 \%$ mortality rate over the years. Our lower-risk group (score $<4$ ) is characterized by a lower rate of perioperative death and longer survival.
\end{abstract}

Gabriele Piffaretti

gabriele.piffaretti@uninsubria.it

1 Vascular Surgery, Department of Medicine and Surgery, University of Insubria School of Medicine, Via Guicciardini, 9, 21100 Varese, Italy

2 College of Medicine, University of Houston, Houston, TX, USA 


\section{Graphic abstract}
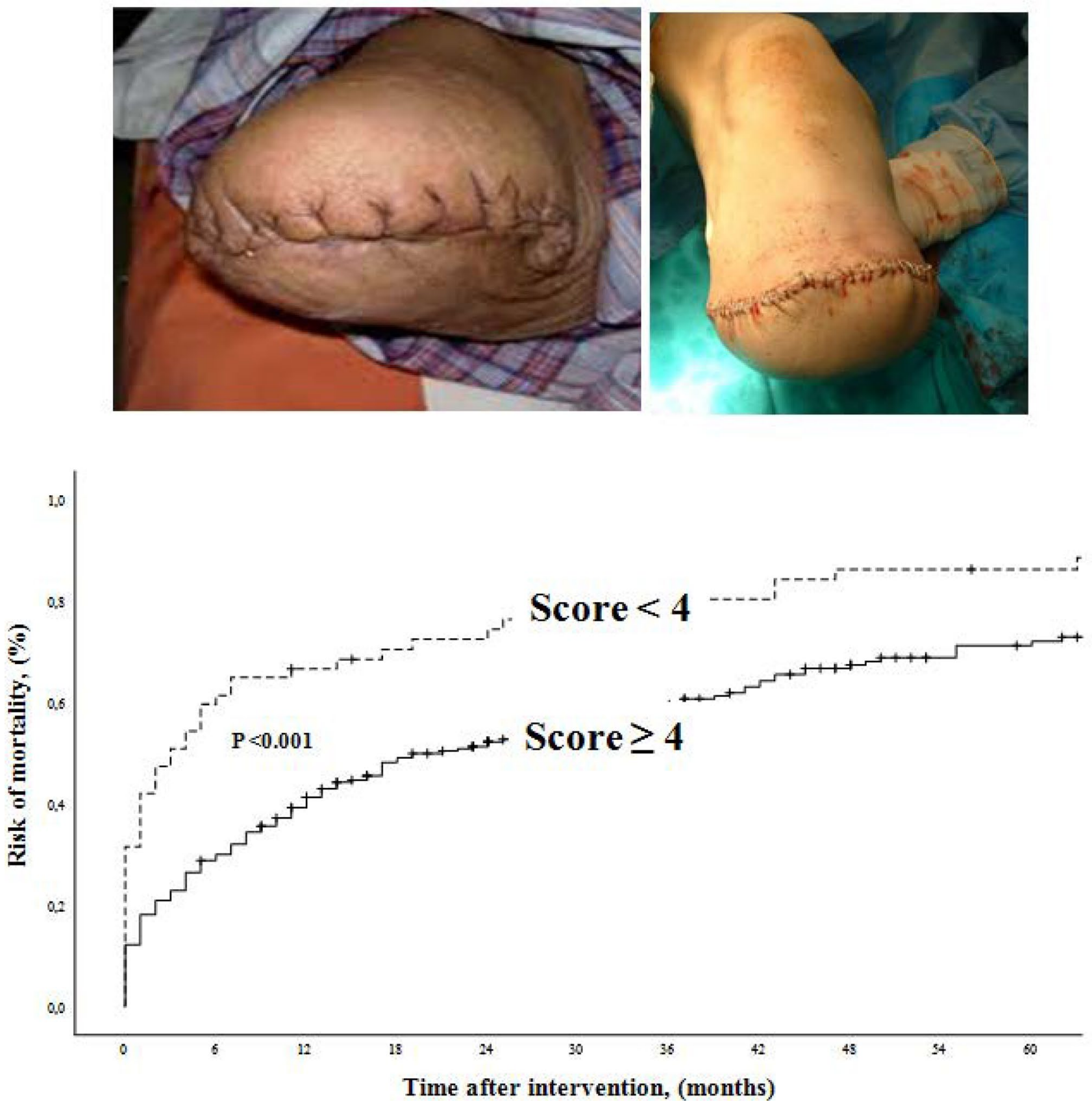

Keywords Major amputation $\cdot$ Gangrene $\cdot$ Critical limb ischemia $\cdot$ Acute limb ischemia $\cdot 30$-day survival

\section{Introduction}

Patients who undergo major lower extremity amputation (mLEA) secondary to peripheral arterial occlusive disease (PAOD) have been reported to have a poor prognosis, likely due to the significant comorbidities and risk factors that exist in this population $[1,2]$. Despite the decline in postoperative short-term mortality, no significant uniform improvement over time was observed at mid-to-long term follow-up [3, 4].

Prevention, early diagnosis, and aggressive medical and surgical treatment for patients with severe PAOD or infection has been studied, however, mortality rates remain high $[3,4]$. Therefore, perioperative risk stratification may play a 
key role in patient counseling and improving postoperative outcomes [5-7].

The aims of this study were to analyze major clinical outcomes while identifying predictors of mortality to generate a risk index score in a contemporary cohort of patients after a first amputation for PAOD and/or infection.

\section{Materials and methods}

\section{Study cohort}

This is a single-center, retrospective, observational cohort study from a tertiary referral university hospital. We followed the checklist of items recommended by the STROBE statement [8]. For this study, all patients treated with above-the-knee amputation (AKA) or belowthe-knee amputation (BKA) between January 1st, 2010 and June 30th, 2018 were identified. Post-hoc analysis identified those who underwent mLEA for PAOD, gangrene, infected non-healing wound. Medical records were reviewed by two senior surgeons (MF and GP). A consort diagram indicating all patients who underwent amputation during the period of study, including the study cohort from which this series was derived is reported in Fig. 1. People with a previous amputation distal to, and including, ankle disarticulation were included in the final analysis. Data collected included demographics, comorbidities, severity of PAOD, surgical history, blood test (haemoglobin, leukocyte count, C-reactive protein,

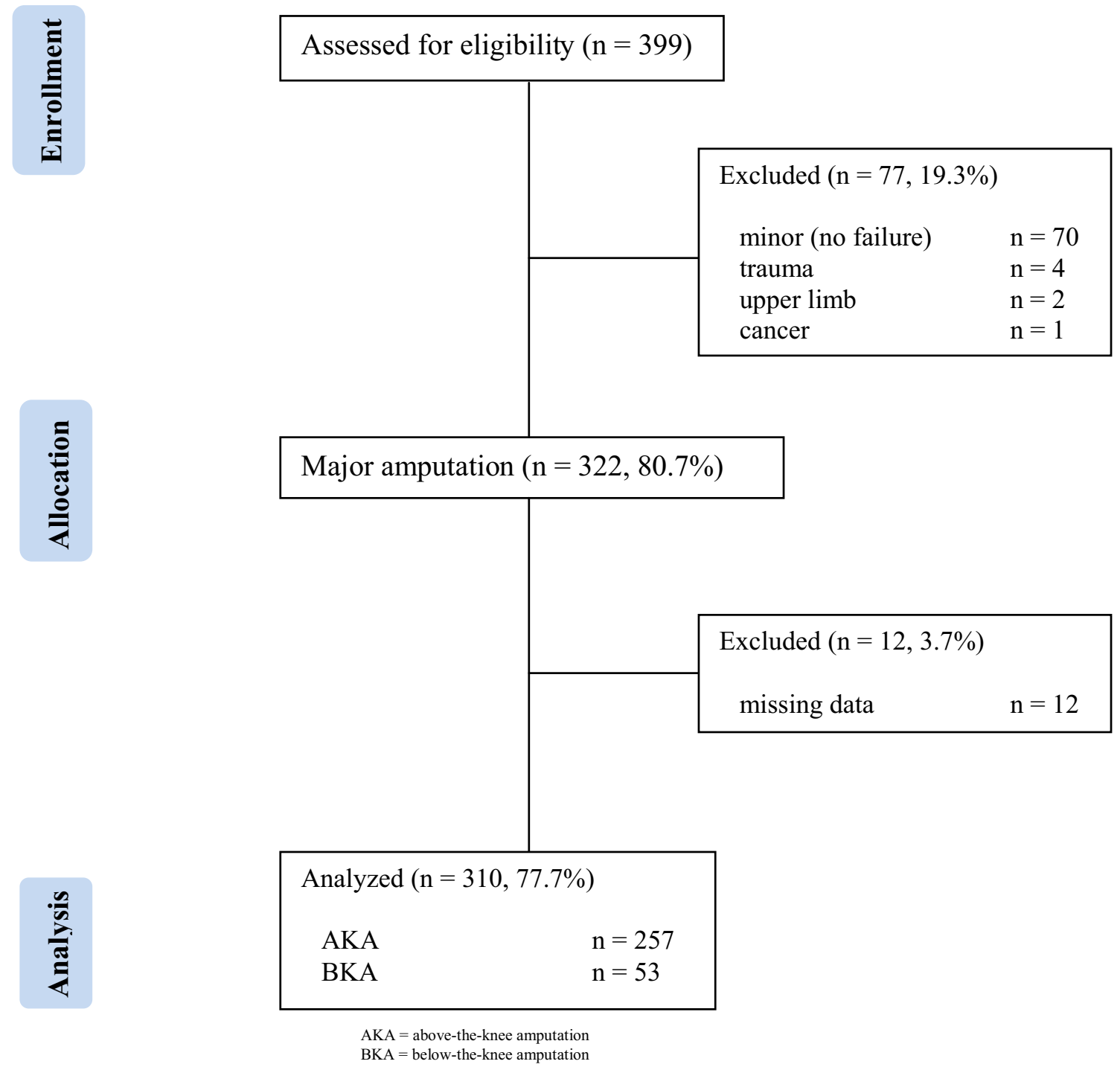

Fig. 1 Consort diagram of lower extremity amputations during the period of study (January 1st 2010-June 30th 2018; $n=$ number; $A K A$ abovethe-knee; $B K A$ below-the-knee) 
albumin) operative details (type of anaesthesia, duration of intervention, level of amputation), as well as postoperative events (amputation revision and mortality) during hospitalization and follow-up period. Owing to the retrospective nature of the present study, local Ethical Committee approval was not necessary according to the Italian National Policy in the matter of Privacy Act on retrospective analysis of anonymized data.

\section{Indication for interventions}

Informed consent for prospective data collection and surgical intervention was signed by each patient. The interventions were performed according to the national guidelines of the Italian Society for Vascular and Endovascular Surgery (SICVE), which are consistent with the clinical practice guidelines on the diagnosis and treatment of PAOD of the European Society for Vascular Surgery (ESVS) [9, 10]. In general, primary amputation was performed in patients with extremely limited life expectancy, extensive necrosis or infectious gangrene, non-ambulatory status. Secondary amputation was performed when revascularization attempts failed and re-intervention was no longer possible because of the absence of a target vessel, or when the limb continued to deteriorate because of infection or necrosis despite adequate blood flow and optimal medical management. The level of amputation was determined based on the clinical judgment of the multidisciplinary team (vascular surgeon and anesthesiologist). Factors assessed included pre-existing limb-threatening ischemia and/or infection and decreased likelihood of salvageability. Computed tomography angiography magnetic resonance, or conventional angiography was not routinely performed to dictate the level of amputation. Indications for the choice of AKA rather than BKA included extensive gangrene or infection, flexion contracture of the knee $\geq 30^{\circ}$, or pre-existing prolonged non-ambulatory status. The type of anesthesia (general vs. spinal/epidural) was at anesthesiologist's judgment. All patients received perioperative antibiotics. Patients who had no tissue loss or infection received short-term use of cefazolin (2gr b.i.d.; Cefamezin-Pfizer; Milan-IT). Those with tissue loss or infection received broad-spectrum antibiotics consisting of a glycopeptide (Vancotex ${ }^{\circledR}$-Pharmatex; Milano-IT) and penicillin/beta-lactamase inhibitor (Textazo ${ }^{\circledR}$-Pharmatex; Milano-IT), unless there was microbiological data already available with drug sensitivities. Postoperatively, electrocardiograms and cardiac enzyme analysis were performed. Generally, routine intensive care unit admission was not indicated per protocol, while rehabilitation transfer was offered to almost all patients to reach personalized outcomes.

\section{Definition and primary outcomes}

Medical comorbidity grading system and operative outcomes were defined according to the Society for Vascular Surgery (SVS) [11]. Chronic kidney disease was defined in agreement with the clinical practice guidelines of the Kidney Disease Improving Global Outcomes [12]. Chronic obstructive pulmonary disease was defined accordingly to the GOLD executive summary [13]. Rutherford classification was used to define critical limb ischemia (CLI) or acute limb ischemia (ALI) [9-11]. Patient's frailty was assessed using the modified Frailty Index (mFI) [7]. The mFI consists of eleven parameters which generate a frailty score, by giving 1 point for each component and a maximum score of 11.Frailty patient was classified who had a cutoff of $\mathrm{mFI}>2$ [7]. Failure of the initial amputation was defined as the need for conversion to a higher level. Conversion of BKA to AKA was performed for failed BKA, defined as the presence of non-healing tissues with extensive deep infection or wound disruption, or extensive stump tissue ischemia. The ClavienDindo grading system was used to classify postoperative complications [14]. Follow-Up Index (FUI) describes follow-up completeness at a given study end date as a ratio between the investigated and the potential follow-up period [15]. Through December 2020, information on reintervention, vital status, and date of death of individual patients were validated by death certificate, electronic charts managed by the regional health care system, or certified data from Emergency Department admission. For this study, the primary outcome of interest was early ( $\leq 30$ days) mortality. Secondary outcomes were postoperative complications and freedom from amputation stump revision/failure. Time to death was calculated from the date of the first amputation.

\section{Statistical analysis [16]}

Clinical data were recorded and tabulated in Microsoft Excel (Microsoft Corp-Redmond; Wash-USA) database. Statistical analysis was performed by means of SPSS 26.0 for Windows (IBM SPSS—Chicago; Ill-USA). Considering the reported median $9 \%$ rate mortality at 30 -days, an $a$ cutoff of 0.05 and a power of $90 \%$, for a $15 \%$ expected mortality our cohort would have enrolled a total of 288 patients. Categorical variables were presented using frequencies and percentages. Continuous variables were presented with mean \pm standard deviation (SD), or median with interquartile range (IQR) and ranges, based on data distribution. Categorical variables were analyzed with the $\chi^{2}$ test, and Fisher's exact test when appropriate. Continuous variables were tested for normal distribution by the Shapiro-Wilk's test and compared between groups with unpaired Student's $T$-test for normally distributed values; otherwise, the Mann-Whitney $U$ test was used. Tukey's honest significance test was 
used as single-step multiple comparison to find a significant difference among means. Univariate analysis was used to identify potential predictors of mortality at 30 -days. Associations that yielded a $P$ value $<0.20$ on univariate screen were then included in a binary logistic regression analysis using the Wald's forward stepwise model. The strength of the association of variables with mortality was estimated by calculating the odd ratio (OR) and $95 \%$ confidence intervals [ $(95 \% \mathrm{CI})$ : significance criteria 0.25 for entry, 0.05 for removal)]. Model discrimination was evaluated by using the area under the receiver operating characteristic (AUROC) curve, with $\geq 0.7$ being considered significantly accurate. A risk score for mortality at 30-days was then constructed by dividing the $\beta$-coefficient of each significant predictor by 0.25 and then by rounding off to the nearest integer value. Cox's regression analysis was used to assess the strength of the association of covariates with mortality. First, the univariate analysis to identify potential predictors of mortality using the Kaplan-Meier survival estimates and logrank test for each covariate. Associations that yielded a $P$ value $<0.20$ on univariate screen were then included in a forward regression analysis, and the strength of association between covariates and mortality was estimated by calculating the hazard ratio (HR) and 95\% CIs. All survival analyses were estimated with the Kaplan-Meier test and reported as percentage \pm standard error (SE) with $95 \% \mathrm{CI}$. All reported $P$ values were two-sided; $P$ value $<0.05$ was considered significant.

\section{Results}

\section{Study cohort}

During the study period, we identified 310 (77.7\%) mLEAs performed on 286 patients. This group consisted of 188 (65.7\%) men and 98 (34.3\%) women. Considering the entire cohort, the median age was 79 years (IQR 69-83). Demographic data, comorbidities, and risk factors are reported in Table 1. The median mFI was 4 (IQR 3-6). Indications for major amputation were as follow: CLI in 235 (75.8\%), ALI in 46 (14.8\%), and infection in 29 (9.4\%) unrelated to PAOD. There were 163 (52.6\%) primary amputations and $147(47.4 \%)$ secondary amputations. We performed 257 (82.9\%) AKA and 53 (17.1\%) BKA. In 70 (22.6\%) cases, a prior ipsilateral minor amputation had been performed. The intervention was performed under general anesthesia in 212 (68.4\%) cases and with spinal/epidural in 98 (31.6\%).

\section{Early outcomes ( $<30$ days)}

There were no intraoperative deaths. Duration of the intervention was $<60 \mathrm{~min}$ in $158(50.9 \%)$ patients and $>60 \mathrm{~min}$
Table 1 Demographic data, comorbidities, and risk factors of the entire cohort $(n=310)$

\begin{tabular}{ll}
\hline Covariate & Patients $(n=310)$ \\
\hline Demographic data & \\
M:F (ratio) & $202: 108$ \\
Age $(n, \%)$ & \\
$<60$ years & $31(10.0)$ \\
$61-70$ & $49(15.8)$ \\
$71-80$ & $93(30.0)$ \\
$\geq 80$ years & $137(44.2)$ \\
Comorbidity $(n, \%)$ & \\
Hypertension & $263(84.8)$ \\
Diabetes & $185(59.7)$ \\
Chronic obstructive pulmonary disease* & $89(28.7)$ \\
Coronary artery disease ${ }^{\circ}$ & $201(64.8)$ \\
Chronic kideny disease & \\
Hemodialysis & $113(36.5)$ \\
Congestive heart insufficiency & $51(16.5)$ \\
Atrial fibrillation & $99(31.9)$ \\
Stroke & $96(31,0)$ \\
Risk factor $(n, \%)$ & $37(11.9)$ \\
Previous Vasc Surg & \\
PAOD surgery & $219(70.6)$ \\
Previous ipsilateral minor amputation & $70(22.6)$ \\
mFI (median, IQR ${ }^{\S}$ & $4(3-6)$ \\
BMT ongoing & $194(62.6)$ \\
Blood tests & $10.2 \pm 1.8(8.9-13.7)$ \\
Hemoglobin, mean \pm SD (range; g/dL) & $15.1 \pm 5.0(3.64-41.7)$ \\
Leukocytes, mean \pm SD (range; $\left.10^{9} / \mathrm{L}\right)$ & $230 \pm 79(2.8-464.5)$ \\
C-reactive protein, mean \pm SD (range; mg/dL) & $1.8(0.8-2.28)$ \\
Albumin, median $(\mathrm{IQR}, \mathrm{g} / \mathrm{dL})$ & \\
\hline & \\
\hline
\end{tabular}

$M$ male; $F$ female; $n$ number; $S D$ standard deviation; $I Q R$ interquartile; Vasc Surg Vascular Surgery history; $P A O D$ peripheral arterial occlusive disease; $m F I$ modified Frailty Index; $B M T$ best medical therapy

*Am J Respir Crit Care Med 2013;187:347-365

${ }^{\circ}$ Am J Kidney Dis 2014;63:713-735

J Vasc Surg 2016;64:e1-e21

$\S_{\text {J Vasc Surg 2017;65:804-811 }}$

in 152 (49.1\%). The median length of hospitalization was 8 days (IQR 5-15 days). Complications were observed in $42(13.5 \%)$ cases, which are described in Table 2. An intervention performed for Rutherford stage 5-6 (OR 10.3, 95\% CI $2.20-47.76 ; P=0.003)$ and BKA (OR $3.88,95 \%$ CI $1.58-9.54 ; P=0.012$ ) was independently associated with the development of a postoperative complication. Early death occurred in $49(15.8 \%)$ patients with the causes of death listed in Table 3. Early mortality did not differ among the different quartiles of age $(15.4 \%$ vs. $14.3 \%$ vs. $15.4 \%$ vs. $19.5 \%, P=0.826)$. Binary logistic regression analysis identified three predictive variables associated 
Table 2 Postoperative complication classified with the Clavien-Dindo severity grade system

\begin{tabular}{llc}
\hline Severity grading* & Complication (type) & Events $(n, \%)$ \\
\hline Grade I/I $\mathrm{d}$ & Surgical site infection & $19(6.1)$ \\
& Wound dehiscence & $7(2.2)$ \\
Grade II & Pneumonia & $2(0.6)$ \\
& Pulmonary oedema & $2(0.6)$ \\
Grade $\mathrm{III}_{\mathrm{b}}$ & Wound infection & $4(1.2)$ \\
& Ab ingestis & $1(0.3)$ \\
& Wound dehiscence & $1(0.3)$ \\
Grade $\mathrm{IV}_{\mathrm{a}, \mathrm{b}}$ & Septic shock & $1(0.3)$ \\
& ARDS & $1(0.3)$ \\
Grade V & Septic shock & $3(0.9)$ \\
& Cardiogenic shock & $1(0.3)$ \\
\hline
\end{tabular}

$N$ number; $A R D S$ acute respiratory distress syndrome

*Ann Surg 2004;240: 205-213

Table 3 Causes of early death

\begin{tabular}{ll}
\hline Cause of death & $n=49(\%)$ \\
\hline Cardiovascular & \\
AMI/CHI/PE/GI infarction & $25(51)$ \\
Multiple organ failure & $14(28.6)$ \\
Sepsis & \\
Septic shock/pneumonia & $4(8.2)$ \\
Renal & $3(6.1)$ \\
AKI/acute on CKD & \\
Respiratory & $3(6.1)$ \\
ARDS/acute on COPD
\end{tabular}

$A M I$ acute myocardial infarction; $C H I$ congestive heart insufficiency; $P E$ pulmonary embolism; $G I$ small bowel/colonic infarction; $A K I$ de novo acute kidney injury; $C K D$ chronic kidney disease; $A R D S$ acute respiratory distress syndrome; $C O P D$ chronic obstructive pulmonary disease

with 30-day mortality: age $>80$ years (OR $2.24,95 \%$ CI $1.17-4.31 ; P=0.015)$, chronic obstructive pulmonary disease (OR 2.12, 95\% CI 1.11-4.06; $P=0.023$ ), and hemodialysis (OR 2.52, 95\% CI 1.15-5.52; $P=0.021$ ), listed in Table 4 . The integer score assigned to each covariate was used to calculate an individual risk score for mortality at 30 days. The score ranged from 0 to 10 (median 3; IQR 0-4) owing to the sum of the three predictors (Table 5). On the basis of the assigned score, we identified two subgroups with varying mortality rates at 30 days: a lower-risk subgroup (score $<4,10.8 \%$ ) and a higher-risk subgroup (score $\geq 4$ : $28.7 \%$; OR 3.2, 95\% CI 1.63-6.32; $P<0.001$ compared to the lower-risk group). The ROC analysis (AUROC $0.66,95 \%$ CI $0.58-0.75$ ) had reasonably good discrimination for the obtained multivariable model (Fig. 2). None of the blood tests nor operative variables were significantly associated with the development of a complication.

\section{Late outcomes}

During the follow-up period, 175of the 261 (67\%) patients died. The median FUI was 0.3 (IQR 0-1). Median survival was 19 months (IQR 7-43): estimated overall survival was $55.7 \%$ (SE 0.28; 95\% CI 50.2-61.1) at 1-year, 36.6\% (SE 0.29 ; 95\% CI 31.1-42.4) at 3-year, and 25.4\% (SE 0.28; 95\% CI 20.3-31.2) at 5-year (Fig. 3). Long-term survival was different between the two categories of risk for early mortality. The risk of mortality in the higher-risk group was $1.8 \mathrm{x}\left(60.8 \%\right.$ vs. $33.3 \%$; log-rank $\left.\chi^{2}=12.9, P<0.001\right)$ that of the lower-risk group (Fig. 3.). Long-term analysis through the Cox's regression analysis identified four variables associated with mortality: need for AKA (HR 1.61, 95\% CI $1.04-2.50 ; P=0.032$ ), age $>80$ years (HR $1.69,95 \%$ CI 1.28-2.24; $P<0.001$ ), end-stage renal disease (HR 1.37, 95\% CI 1.03-1.82; $P=0.028$ ), and congestive heart failure (HR $1.60,95 \%$ CI $1.22-2.11 ; P=0.001$ ). During the study time period, 24 (7.7\%) patients underwent bilateral major amputation (AKA, $n=13$; BKA, $n=11$ ). Surgical revision of the amputation stump was required in $25(8.1 \%)$ patients. Failure of a BKA to heal occurred in $3(1.1 \%)$ cases at 2, 10 , and 13 months after the initial amputation requiring conversion to an AKA. Freedom from amputation stump revision/failure was similar between BKA and AKA (Log-rank $\left.\chi^{2}=1.77, P=0.183\right)$ as reported in Fig. 4. No preoperative and intraoperative variables were associated with the need for stump revision.

\section{Discussion}

There are three findings of significance in this study: mortality after mLEA remains high and unchanged through the years, risk stratification is not adequately sensitive, and older age (e.g., $\geq 80$ ) is the most concrete predictor of a major adverse outcome following a mLEA.

Year after year, many studies have reported consistently high mortality rates after mELAs, notwithstanding a more aggressive policy toward peripheral revascularization, better medical management, and preoperative optimization, in addition to anesthetic improvements [2, 17-19]. In our experience, early mortality remained unchanged for the past decade and is consistent with the 7.6-22.5\% reported in several real-world experiences, not falling below $14 \%$ in the four quartiles of the period of study (Table 6) [3, 5-7, 17-27]. Our results are similar to Jones et al. [3], who analyzed 186,338 older patients with identified PAOD who underwent mLEA, namely the largest cohort published up to date. Though, there appears to have been a decline in the 
Table 4 Univariate screen and multivariable analysis for early mortality and postoperative complications

\begin{tabular}{|c|c|c|c|c|c|c|}
\hline \multirow[t]{3}{*}{ Covariate } & \multicolumn{6}{|c|}{ Early mortality } \\
\hline & \multicolumn{3}{|c|}{ Univariate } & \multicolumn{3}{|c|}{ Multivariate } \\
\hline & OR & $95 \% \mathrm{CI}$ & $P$ & OR & $95 \% \mathrm{CI}$ & $P$ \\
\hline Age $\geq 80$ & 1.86 & $1.03-3.45$ & 0.059 & 2.24 & $1.17-4.31$ & 0.015 \\
\hline CKD & 1.52 & $0.82-2.82$ & 0.189 & & & \\
\hline Hemodialysis & 1.85 & $0.89-3.85$ & 0.139 & 2.52 & $1.15-5.52$ & 0.021 \\
\hline COPD & 1.92 & $1.02-3.60$ & 0.057 & 2.12 & $1.11-4.06$ & 0.023 \\
\hline BMT & 0.63 & $0.34-1.16$ & 0.149 & & & \\
\hline Vasc Surgery history & 1.33 & $1.03-1.74$ & 0.016 & & & \\
\hline \multirow[t]{3}{*}{ Covariate } & \multicolumn{6}{|c|}{ Postoperative complication } \\
\hline & \multicolumn{3}{|c|}{ Univariate } & \multicolumn{3}{|c|}{ Multivariate } \\
\hline & OR & $95 \% \mathrm{CI}$ & $P$ & OR & $95 \% \mathrm{CI}$ & $P$ \\
\hline BKA & 1.33 & $1.06-1.68$ & 0.002 & 3.88 & $1.58-9.54$ & 0.003 \\
\hline CLI (stage 5-6) & 2.26 & $1.20-3.01$ & 0.015 & 10.23 & $2.20-47.76$ & 0.03 \\
\hline Age $>80$ & 2.23 & $1.23-4.03$ & 0.001 & & & \\
\hline Hemodialysis & 2.02 & $0.94-4.35$ & 0.075 & & & \\
\hline BMT & 2.44 & $1.12-5.30$ & 0.025 & & & \\
\hline Duration intervention & 2.99 & $1.47-6.09$ & 0.002 & & & \\
\hline
\end{tabular}

$O R$ odd ratio; $C I$ confidence interval; $C K D$ chronic kidney disease; $C O P D$ chronic obstructive pulmonary disease; Vasc Surgery Vascular Surgery history; $B K A$ below-the-knee amputation; $C L I$ critical limb ischemia; $B M T$ best medical therapy

Table 5 Proposed preliminary score for early mortality estimate

\begin{tabular}{llll}
\hline Covariate & $\beta$-coefficient & \multicolumn{2}{l}{$\begin{array}{l}\text { Integer score } \\
\text { calculation }\end{array}$} \\
\cline { 3 - 4 } & & Yes & No \\
\hline Age $\geq 80$ & 0.81 & 3 & 0 \\
Hemodialysis & 0.92 & 4 & 0 \\
COPD & 0.75 & 3 & 0 \\
\hline
\end{tabular}

COPD chronic obstructive pulmonary disease

short-term, mortality rates were similar at the beginning and end of his study never falling below $12.7 \%$. One must also consider the fact that nearly $63 \%$ of our patients were on best medical therapy at the time of mLEA, underscoring how truly frail are these patients [19].

Despite the large number of mLEAs performed every year, risk stratification in this clinical context is still meager $[5,7]$. Since no single clinical or physiologic parameter has been able to reliably predict a poor outcome after mLEA, the use of a risk-prediction score may be a more accurate method to optimize the risk stratification [27]. Taking advantage of the large number of patients contained in the American College of Surgeons National Surgical Quality Improvement Program, Easterlin et al. [5] aimed to create a risk index to predict 30-day mortality after mLEAs for PAOD. Their scoring system included eleven covariates and showed to have similar discriminatory power to several renowned risk scores used to predict surgical outcomes. The risk score developed from our cohort relies on fewer covariates, thus simplifying the process, but decreasing the accuracy shown by our model. However, our findings are worthy of several observations and conclusions. First, it constitutes our institutional audit, which is an important method of professional quality improvement based on examination of outcomes and correction of substandard practice [28]. Secondly, the covariates identified by our model have been already confirmed to be associated with mortality after mLEAs in several experiences, thus known and reliable predictors [1, $3,5,18,29-31]$. Third, the model allowed us to generate two markedly different categories of risk for early mortality, a distinction that was also associated with a significant difference in long-term survival in favor of the lower-risk group [5]. This could mean that lower-risk patients, those who are least likely to die, are the ones most likely to survive longer. In light of the fact that overall early mortality has been unchanged over the years, and the fact that patients within the lower-risk category are those who benefit from longer survival, we may have to reverse how to interpret the significance of our score model. Although our results must find future confirmation, patients who are more likely to survive the past 30-days might benefit from additional improvement of the intensity of perioperative care, which could ultimately further improve survival rates. Better perioperative 
Fig. 2 Receiver operating characteristic curve for the multivariate model evaluating the risk score for mortality at 30 days (AUROC area under the receiver operating characteristic curve)

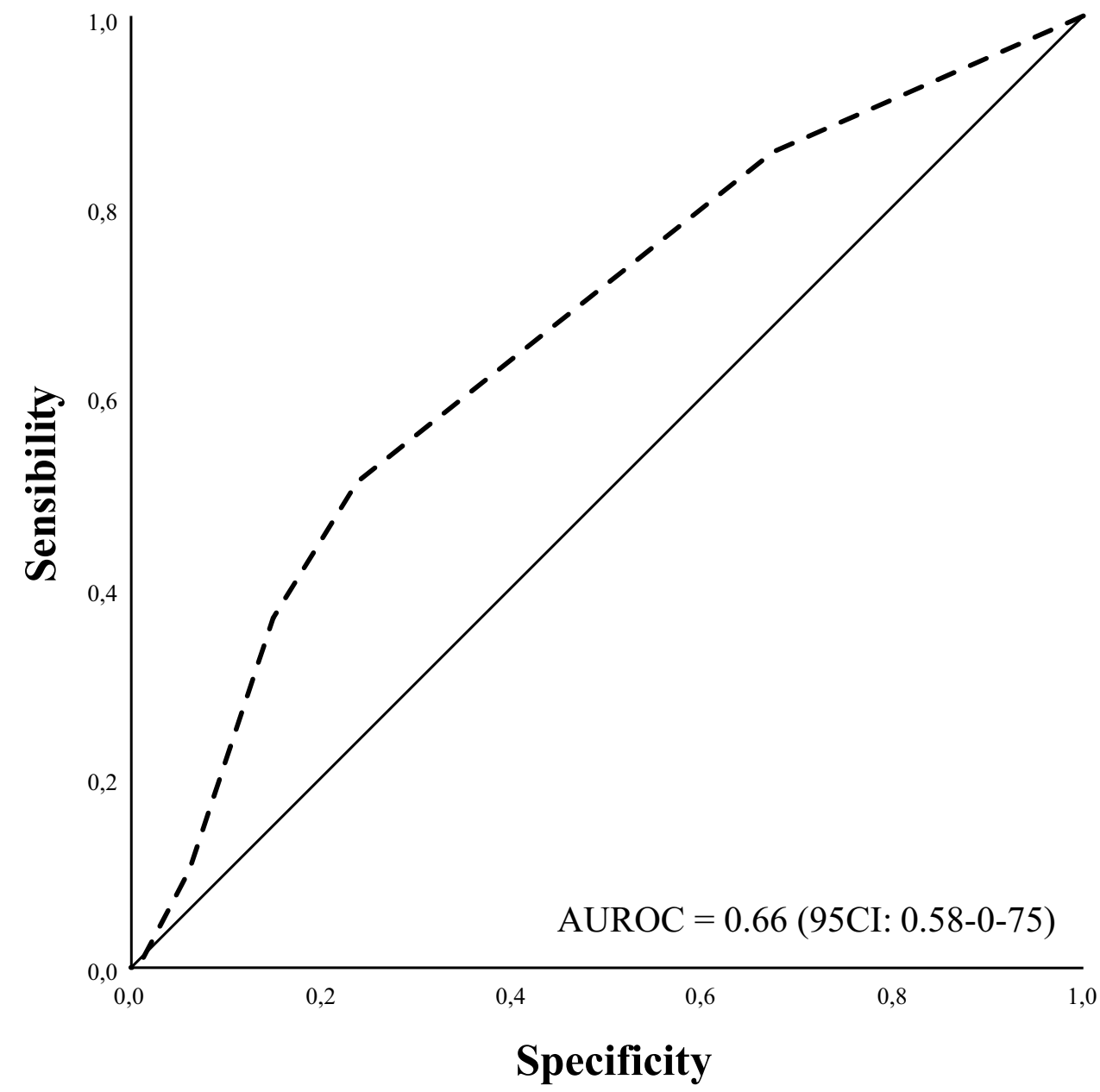

care could be centered on specific risk factors, optimization of blood tests, medical therapy enhancement, and also taking advantage of delaying a non-urgent intervention [3, 6, 32].

The literature is abundant with studies confirming that older age is an important predictor for adverse outcomes [1, $3,5,18]$. Therefore, it is not surprising that older age, specifically $\geq 80$ years, has been shown to be the most important predictor of mortality following mLEAs [33]. In particular, it is interesting to note that in the index score built by Easterlin et al. [5],this same age distinction was their most powerful covariate. Despite all commendable attempts to refine risk stratification, we are undoubtedly in need of a more accurate risk prediction system. Nevertheless, non-operative management in high-risk patients should still be avoided if possible [6]. We hope our findings may lead to further initiatives on this aspect.

Amputation level remains critical to outcomes. In this study, an AKA was more frequently associated with mortality compared to a BKA, a result similar to several other investigators [3, 17, 19, 24]. Indeed, the difference between the two groups seems to be mainly determined by the risk profile of our patients. However, while prior investigators have reported that an increased perioperative mortality rate in AKA patients was associated with the presence of advanced ischemia, the most determining factor for AKA in our experience was older age [5, 19]. On one hand, it further underlines the impact of age on mLEA outcomes as BKA patients had a higher incidence of diabetes, chronic kidney disease, or hemodialysis [17, 26, 30, 31]. The association of these comorbidities with BKA is the main rationale as to why a BKA was significantly associated with postoperative complications, and more frequently required proximal revision surgery because of stump failure [17].

Considering their overall frailty status, patients needing mLEA for PAOD have been shown to be at high-risk for major adverse events. In our experience, most of the interventions have been performed under general anesthesia which can be considered a potential risk factor in these patients [34]. In our experience the type of anesthesia did not impact negatively on both major outcomes. While older studies reported a potential benefit of regional anesthesia in comparison with general anesthesia, our result data finds support in several recent experiences which reported the mode of anesthesia, did not have a significant effect on 


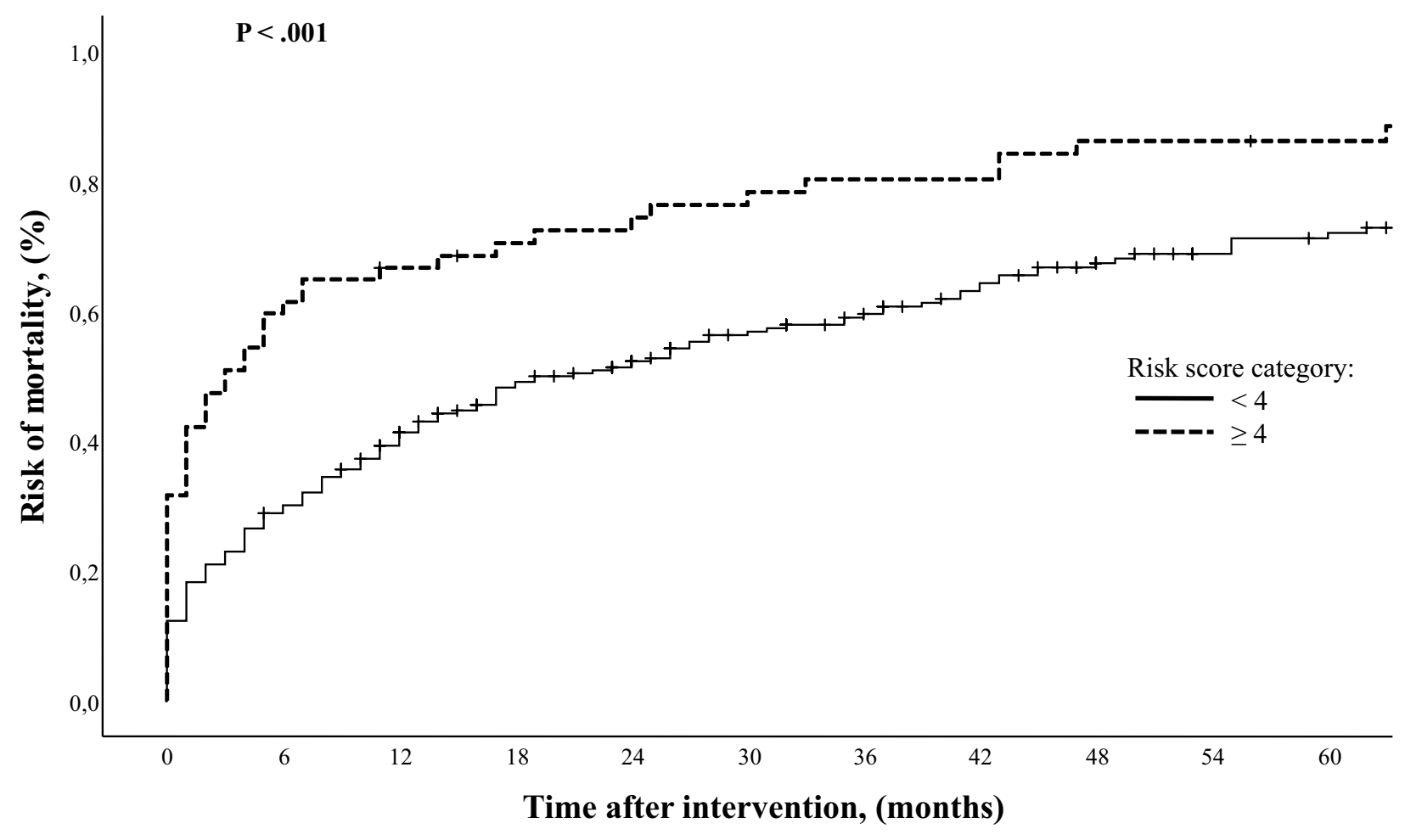

Fig. 3 Risk analysis stratified by risk score categories

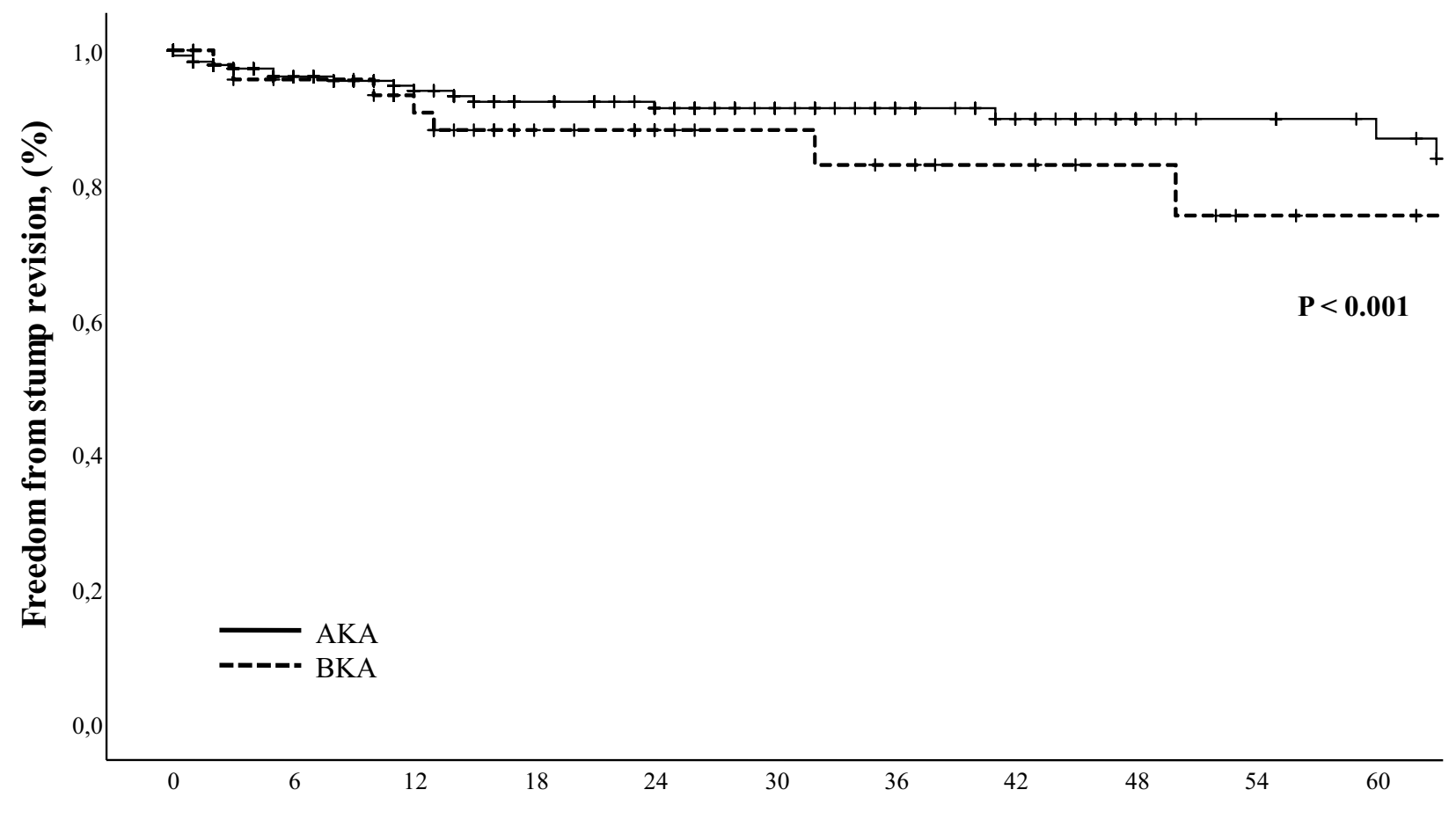

Time after intervention, (months)

Fig. 4 Kaplan-Meier estimates of survival stratified by level of amputation ( $A K A$ above-the-knee; $B K A$ below-the-knee) 
Table 6 Summary of the literature including the largest experiences reporting on major lower extremity amputations and mortality analyses

\begin{tabular}{|c|c|c|c|c|c|c|}
\hline \multirow[t]{2}{*}{ Author } & \multirow[t]{2}{*}{ Type of study } & \multirow[t]{2}{*}{ Period of study (years) } & \multirow[t]{2}{*}{ Patients $(n)$} & \multicolumn{3}{|l|}{ Mortality } \\
\hline & & & & 30-days (\%) & 1 year $(\%)$ & 5 years $(\%)$ \\
\hline Jones et al. [3] & Medicare & 2000-2008 & 186.388 & 13.5 & 43.8 & \\
\hline Easterlin et al. [5] & ACS-NSQIP & $2005-2009$ & 9.244 & 8.1 & & \\
\hline Wise et al. [6] & Single center & 2004-2013 & 295 & 9 & & \\
\hline Fang et al. [7] & Single center & 2010-2015 & 379 & 22.5 & & \\
\hline Aulivola et al. [17] & Single center & $1990-2001$ & 788 & 8.6 & 30.3 & 65.3 \\
\hline Fortington et al. [18] & Multicenter & 2010-2011 & 299 & 22 & 44 & 77 \\
\hline Gabel et al. [19] & VQI & $2013-2015$ & 2.939 & 5 & & \\
\hline Stone et al. [20] & Single center & 1999-2003 & 380 & 15.5 & & \\
\hline Davenport et al. [21] & ACS-NSQIP & 2005-2009 & 6.188 & 7.6 & & \\
\hline Karam et al. [22] & VA-NSQIP & 2005-2008 & 6.839 & 9.1 & & \\
\hline Sha et al. [23] & Single center & 2004-2009 & 454 & 9.2 & 30 & 40 \\
\hline Rosen et al. [24] & Single center & 2007-2010 & 289 & 16.7 & 44 & \\
\hline Morisaki et al. [25] & Single center & $2008-2015$ & 106 & 7.6 & 36.5 & 63.4 \\
\hline Aljarrah et al. [26] & Single center & 2012-2017 & 140 & & 30.7 & \\
\hline
\end{tabular}

$n$ number; VQI vascular quality initiative; VA-NSQIP Veterans Administration National Surgical Quality Improvement Program; ACS-NSQIP American College of Surgeons National Surgical Quality Improvement Program

perioperative outcomes after mLEA [5, 19, 22, 29, 34]. Although it is difficult to give an unquestionable explanation, the combination of advancement in perioperative care and anesthesia management along with multidisciplinary evaluation might have been beneficial on tempering worse outcome with a specific anesthesia regimen [34].

\section{Limitations}

The present study has several limitations. It is retrospective in nature, the sample size is small and prospective evaluation of the risk score is needed to clarify the potential utility in the decision process. Nonetheless, although large databases have significant value through increased power and sample size, a single institutional analysis may offer granular detail that may not be available in the larger study. All operations were managed by members of our service only and not by different divisions or departments. Although all these features may not allow for the generalizability of our findings, our data compare well with the available literature owing to the consistency of follow-up data validated by official health documents and will allow us to further refine our processes and perform continuous quality improvement.

\section{Conclusions}

In our experience, mLEAs continue to be associated with a disturbingly high mortality rate that remains greater $14 \%$ over the years. Our predictive score discriminated two categories of patients with significantly different risks of early mortality and long-term survival. In particular, the group with a score $>4$ is characterized by significantly higher early as well as long-term mortality: in these patients, major amputation likely represents a marker of advanced illness that significantly limit survival independently of the possibility to perform this intervention. Therefore, prospective validation will help to refine our risk stratification and treatment policy for these patients who would also potentially represent a logical population to engage in a proactive discussion of end-of-life.

Author contributions Each Author equally contributed to data acquisition and storage, analysis, paper writing, critical final revision as well as is accountable for responsibility. Study design: GP, MF, NR. Data collection: VP, MF, MCC, GM, GP. Data analysis: GP, MF. Writing: GP, RB. Critical revision and final approval: MF, MCC, VP, GM, NR, CI, MT, GP, RB.

Funding Open access funding provided by Università degli Studi dell'Insubria within the CRUI-CARE Agreement. The authors report no involvement in the research by the sponsor that could have influenced the outcome of this work. This paper was unfunded.

Data availability Fully available; surgeons are responsible for data capture, insertion, and auditing.

Code availability Microsoft Excel (Microsoft Corp-Redmond; Wash-USA).

\section{Declarations}

Conflicts of interest The authors declare that they have no conflict of interest. 
Ethical approval Owing to the retrospective nature of the present study, local Ethical Committee approval was not necessary according to the Italian National Policy in the matter of Privacy Act on retrospective analysis of anonymized data.

Consent to participation The patient or family consented their participation.

Consent for publication Patient or family consented for publication.

Informed Consent Informed consent was not necessary in view of the retrospective nature of the study.

Research involving human participants and/or animals This study involved human research participants.

Open Access This article is licensed under a Creative Commons Attribution 4.0 International License, which permits use, sharing, adaptation, distribution and reproduction in any medium or format, as long as you give appropriate credit to the original author(s) and the source, provide a link to the Creative Commons licence, and indicate if changes were made. The images or other third party material in this article are included in the article's Creative Commons licence, unless indicated otherwise in a credit line to the material. If material is not included in the article's Creative Commons licence and your intended use is not permitted by statutory regulation or exceeds the permitted use, you will need to obtain permission directly from the copyright holder. To view a copy of this licence, visit http://creativecommons.org/licenses/by/4.0/.

\section{References}

1. Stern JR, Wong CK, Yerovinkina M, Spindler SJ, See AS, Panjaki $S$ et al (2017) A meta-analysis of long-term mortality and associated risk factors following lower extremity amputation. Ann Vasc Surg 42:322-327. https://doi.org/10.1016/j.avsg.2016.12.015

2. Londero LS, Hoegh A, Houlind K, Lindholt J (2019) Major amputation rates in patients with peripheral arterial disease aged 50 years and over in Denmark during the period 1997-2014 and their relationship with demographics, risk factors, and vascular services. Eur J Vasc Endovasc Surg 58(5):729-737. https://doi. org/10.1016/j.ejvs.2019.06.007

3. Jones WS, Patel MR, Dai D, Vemulapalli S, Subherwal S, Stafford $\mathrm{J}$ et al (2013) High mortality risks after major lower extremity amputation in Medicare patients with peripheral artery disease. Am Heart J 165(5):809-815, 815.e1. https://doi.org/10.1016/j.ahj. 2012.12.002

4. Kelly DA, Pedersen S, Tosenovsky P, Sieunarine K (2017) Major lower limb amputation: outcomes are improving. Ann Vasc Surg 45:29-34. https://doi.org/10.1016/j.avsg.2017.05.039

5. Easterlin MC, Chang DC, Wilson SE (2013) A practical index to predict 30-day mortality after major amputation. Ann Vasc Surg 27(7):909-917. https://doi.org/10.1016/j.avsg.2012.06.030

6. Wise ES, McMaster WG Jr, Williamson K, Wergin JE, Hocking KM, Brophy CM (2016) Preoperative predictors of 30-day mortality and prolonged length of stay after above-knee amputation. Ann Vasc Surg 31:124-133. https://doi.org/10.1016/j.avsg.2015. 08.017

7. Fang ZB, Hu FY, Arya S, Gillespie TW, Rajani RR (2017) Preoperative frailty is predictive of complications after major lower extremity amputation. J Vasc Surg 65(3):804-811. https://doi.org/ 10.1016/j.jvs.2016.10.102
8. von Elm E, Altman DG, Egger M, Pocock SJ, Gøtzsche PC, Vandenbroucke JP, Initiative STROBE (2007) The Strengthening the Reporting of Observational Studies in Epidemiology (STROBE) statement: guidelines for reporting observational studies. Epidemiology 18(6):800-804. https://doi.org/10.1097/EDE.0b013 e3181577654

9. Björck M, Earnshaw JJ, Acosta S, Bastos Gonçalves F, Cochennec F, Debus ES et al (2020) European Society for Vascular Surgery (ESVS) 2020 clinical practice guidelines on the management of acute limb ischaemia. Eur J Vasc Endovasc Surg 59(2):173-218. https://doi.org/10.1016/j.ejvs.2019.09.006

10. Aboyans V, Ricco JB, Bartelink MEL, Björck M, Brodmann M, Cohnert T et al (2018) 2017 ESC Guidelines on the Diagnosis and Treatment of Peripheral Arterial Diseases, in collaboration with the European Society for Vascular Surgery (ESVS). Eur J Vasc Endovasc Surg 55(3):305-368. https://doi.org/10.1016/j. ejvs.2017.07.018

11. Stoner MC, Calligaro KD, Chaer RA, Dietzek AM, Farber A, Guzman RJ et al (2016) Reporting standards of the Society for Vascular Surgery for endovascular treatment of chronic lower extremity peripheral artery disease. J Vasc Surg 64(1):e1-e21. https://doi.org/10.1016/j.jvs.2016.03.420

12. Inker LA, Astor BC, Fox CH, Isakova T, Lash JP, Peralta CA et al (2014) KDOQI US commentary on the 2012 KDIGO clinical practice guideline for the evaluation and management of CKD. Am J Kidney Dis 63(5):713-735. https://doi.org/10.1053/j.ajkd. 2014.01.416

13. Vestbo J, Hurd SS, Agustí AG, Jones PW, Vogelmeier C, Anzueto A et al (2013) Global strategy for the diagnosis, management, and prevention of chronic obstructive pulmonary disease: GOLD executive summary. Am J Respir Crit Care Med 187(4):347-365. https://doi.org/10.1164/rccm.201204-0596PP

14. Dindo D, Demartines N, Clavien PA (2004) Classification of surgical complications: a new proposal with evaluation in a cohort of 6336 patients and results of a survey. Ann Surg 240(2):205-213. https://doi.org/10.1097/01.sla.0000133083.54934.ae

15. von Allmen RS, Weiss S, Tevaearai HT, Kuemmerli C, Tinner C, Carrel TP et al (2015) Completeness of follow-up determines validity of study findings: results of a prospective repeated measures cohort study. PLoS ONE 10(10):e0140817. https://doi.org/ 10.1371/journal.pone.0140817

16. Hickey GL, Dunning J, Seifert B, Sodeck G, Carr MJ, Burger HU et al (2015) EJCTS and ICVTS Editorial Committees. Statistical and data reporting guidelines for the European Journal of CardioThoracic Surgery and the Interactive CardioVascular and Thoracic Surgery. Eur J Cardiothorac Surg 48(2):180-193. https://doi.org/ 10.1093/ejcts/ezv168

17. Aulivola B, Hile CN, Hamdan AD, Sheahan MG, Veraldi JR, Skillman JJ et al (2004) Major lower extremity amputation: outcome of a modern series. Arch Surg 139(4):395-399. https://doi. org/10.1001/archsurg.139.4.395

18. Fortington LV, Geertzen JH, van Netten JJ, Postema K, Rommers GM, Dijkstra PU (2013) Short and long term mortality rates after a lower limb amputation. Eur J Vasc Endovasc Surg 46(1):124131. https://doi.org/10.1016/j.ejvs.2013.03.024

19. Gabel J, Jabo B, Patel S, Kiang S, Bianchi C, Chiriano J et al (2018) Vascular quality initiative. Analysis of patients undergoing major lower extremity amputation in the vascular quality initiative. Ann Vasc Surg 46:75-82. https://doi.org/10.1016/j.avsg. 2017.07.034

20. Stone PA, Flaherty SK, Aburahma AF, Hass SM, Jackson JM, Hayes JD et al (2006) Factors affecting perioperative mortality and wound-related complications following major lower extremity amputations. Ann Vasc Surg 20(2):209-216. https://doi.org/10. 1007/s10016-006-9009-z 
21. Davenport DL, Ritchie JD, Xenos ES (2012) Incidence and risk factors for 30-day postdischarge mortality in patients with vascular disease undergoing major lower extremity amputation. Ann Vasc Surg 26(2):219-224. https://doi.org/10.1016/j.avsg.2011.05. 012

22. Karam J, Shepard A, Rubinfeld I (2013) Predictors of operative mortality following major lower extremity amputations using the National Surgical Quality Improvement Program public use data. J Vasc Surg 58(5):1276-1282. https://doi.org/10.1016/j.jvs.2013. 05.026

23. Shah SK, Bena JF, Allemang MT, Kelso R, Clair DG, Vargas L et al (2013) Lower extremity amputations: factors associated with mortality or contralateral amputation. Vasc Endovasc Surg 47(8):608-613. https://doi.org/10.1177/1538574413503715

24. Rosen N, Gigi R, Haim A, Salai M, Chechik O (2014) Mortality and reoperations following lower limb amputations. Isr Med Assoc J 16(2):83-87

25. Morisaki K, Yamaoka T, Iwasa K (2018) Risk factors for wound complications and 30-day mortality after major lower limb amputations in patients with peripheral arterial disease. Vascular 26(1):12-17. https://doi.org/10.1177/1708538117714197

26. Aljarrah Q, Allouh MZ, Bakkar S, Aleshawi A, Obeidat H, Hijazi E et al (2019) Major lower extremity amputation: a contemporary analysis from an academic tertiary referral centre in a developing community. BMC Surg 119(1):170. https://doi.org/10.1186/ s12893-019-0637-y

27. Schanzer A, Mega J, Meadows J, Samson RH, Bandyk DF, Conte MS (2008) Risk stratification in critical limb ischemia: derivation and validation of a model to predict amputation-free survival using multicenter surgical outcomes data. J Vasc Surg 48(6):1464-1471. https://doi.org/10.1016/j.jvs.2008.07.062

28. Lui CW, Boyle FM, Wysocki AP, Baker P, D'Souza A, Faint S et al (2017) How participation in surgical mortality audit impacts surgical practice. BMC Surg 17(1):42. https://doi.org/10.1186/ s12893-017-0240-Z
29. Hasanadka R, McLafferty RB, Moore CJ, Hood DB, Ramsey DE, Hodgson KJ (2011) Predictors of wound complications following major amputation for critical limb ischemia. J Vasc Surg 54(5):1374-1382. https://doi.org/10.1016/j.jvs.2011.04.048

30. Hickson LJ, Rule AD, Thorsteinsdottir B, Shields RC, Porter IE, Fleming MD et al (2018) Predictors of early mortality and readmissions among dialysis patients undergoing lower extremity amputation. J Vasc Surg 68(5):1505-1516. https://doi.org/10. 1016/j.jvs.2018.03.408

31. Arhuidese I, Nejim B, Aji EA, Canner J, Malas MB (2019) Survival after major lower extremity amputation in patients with endstage renal disease. J Vasc Surg 70(4):1291-1298. https://doi.org/ 10.1016/j.jvs.2018.12.055

32. Brown BJ, Attinger CE (2013) The below-knee amputation: to amputate or palliate? Adv Wound Care (New Rochelle) 2(1):30 35. https://doi.org/10.1089/wound.2011.0317

33. Piffaretti G, Angrisano A, Franchin M, Ferrario M, Rivolta N, Bacuzzi A et al (2018) Risk factors analysis of thromboembolectomy for acute thromboembolic lower extremity ischemia in native arteries. J Cardiovasc Surg (Torino) 59(6):810-816. https://doi. org/10.23736/S0021-9509.16.09673-7

34. Moreira CC, Farber A, Kalish JA, Eslami MH, Didato S, Rybin D et al (2016) (2016) The effect of anesthesia type on major lower extremity amputation in functionally impaired elderly patients. $\mathbf{J}$ Vasc Surg 63(3):696-701. https://doi.org/10.1016/j.jvs.2015.09. 050

Publisher's Note Springer Nature remains neutral with regard to jurisdictional claims in published maps and institutional affiliations. 